\title{
Mapeamento dos impactos ambientais dos rejeitos da dragagem do porto do Rio de Janeiro, através de métodos acústicos, em áreas da plataforma continental
}

\author{
Batista, L.S., LAGEMAR-UFF; Porto Silva, D.C., LAGEMAR-UFF; Coelho, V.B.B., LAGEMAR-UFF; Drabinski, T.L., \\ LAGEMAR-UFF; Melo, G.V., LAGEMAR-UFF; Silva,R.C.O., LAGEMAR-UFF; Dias, G.T.M., LAGEMAR-UFF; Baptista Neto, \\ J.A.
}

Copyright 2018, SBGf - Sociedade Brasileira de Geofísica

Este texto foi preparado para a apresentação no VIII Simpósio Brasileiro de Geofísica, Salinópolis, 18 a 20 de setembro de 2018. Seu conteúdo foi revisado pelo Comitê Técnico do VIII SimBGf, mas não necessariamente representa a opinião da SBGf ou de seus associados. É proibida a reprodução total ou parcial deste material para propósitos comerciais sem prévia autorização da SBGf.

\section{Resumo}

Dragar regiões portuárias é algo recorrente, e o monitoramento do rejeito retirado neste processo é algo essencial para minimizar seus impactos. Este trabalho teve como objetivo mapear os impactos ambientais, dos sedimentos dragados do porto do Rio de Janeiro, na plataforma continental rasa da região. Para isso foram utilizados dois métodos geofísicos: sidescan sonar e sísmica de alta resolução. O intuito é correlacionar os dados de ambos os métodos, a fim de obter tanto informações da área de ocupação dos rejeitos no assoalho da plataforma quanto a dispersão dos mesmos.

\section{Introdução}

Acessibilidade dos portos costeiros, portos de pesca e vias navegáveis é vital para o crescimento econômico das regiões costeiras (Regoli et al., 2002; Frenzel, et al., 2009). Infelizmente essas áreas raramente são naturalmente profundas e as profundidades navegáveis devem ser mantidas por repetidas dragagem. Todos os anos, as operações de dragagem geram centenas de milhões de metros cúbicos de sedimentos em todo o mundo, que devem ser descartados e gerenciados de forma economicamente e ambientalmente sustentáveis (Harvey et al., 1998). Dragagem e eliminação de material dragado é um dos maiores e mais importantes problemas ambientais da gestão da zona costeira. A necessidade de dragagem tem sido fortemente influenciada pelo aumento dos requisitos de transporte aquaviário, e do tamanho das embarcações. Como consequência da pressão econômica da navegação, os canais são regularmente dragados para garantir uma profundidade suficiente para uma grande variedade de embarcações. Isto, tal como descrito, acarretou em modificações nos padrões de sedimentação de estuários e baías. Estas atividades vêm provocando, ao longo dos anos, alterações, e afetam a qualidade ambiental dessas regiões uma vez que, além do aporte de sedimentos, vários poluentes industriais e domésticos são despejados, diariamente nas baías e estuários; tornando-os muitas vezes, ambientes bastante degradados (Kjerfve et al., 2001; Baptista Neto et al., 2006). Inicialmente, a delimitação de áreas de descarte de material dragado na plataforma continental do Rio de Janeiro foi proposta por estudos dirigidos pelo INPH, a partir do ano de 1996, em que as áreas de despejos dos materiais dragados oriundos da Baía de Guanabara, passaram a ser autorizados pelo Instituto Estadual do Ambiente - INEA. Para se mapear os sedimentos dragados em locais de mar aberto, denominados áreas de descarte oceânico, conhecidos vulgarmente como "bota-foras" (Pereira, 2013) foi realizado este projeto. Com este objetivo foram realizadas cinco linhas de aquisição, utilizando em conjunto a sísmica de alta resolução com o sonar de varredura lateral, objetivando mensurar o descarte de sedimento dragado do porto do Rio de Janeiro na região de "bota-fora". O objetivo inicial deste projeto previa a diagnose do estado atual do ecossistema da plataforma continental rasa ao largo do litoral entre as praias do Leblon e Itaipuaçu, incluindo a entrada da baía e o entorno das ilhas adjacentes.

\section{Metodologia}

Com o objetivo de estudar a plataforma continental rasa do Rio de Janeiro, adjacente à entrada da Baía de Guanabara, foram feitos cinco perfis sísmico/sonográficos paralelos à costa. Estas linhas foram plotadas na carta náutica e batimetria regional, utilizando-se do software HYPACK 2013, como mostrado na figura 1.

Para a sonografia, o equipamento utilizado foi um sistema digital de sonar de varredura lateral modelo 4100/560P da EdgeTech com sensor (towfish) 272 TD, que emite feixes laterais de ondas acústicas na frequência de 100 ou $500 \mathrm{kHz}$, e um processador digital de alta performance. No presente trabalho a frequência utilizada foi de $100 \mathrm{KHz}$, e o software de aquisição empregado foi o Edgetech Discover 4100. Durante o levantamento foram utilizados "ranges" entre 50 a 100 metros para cada lado da linha navegada.

Para a sísmica rasa de alta resolução foi utilizado um CHIRP, um equipamento composto por um sistema de perfilagem multi-frequência 5100/560P da EdgeTech Inc. 
com sensor (Tow-Fish) de 2,0-16 kHz de frequência modulada. $\mathrm{O}$ sistema foi controlado pelo programa Discover 3.42, que permite a visualização em tempo real da sismoestratigrafia da região.

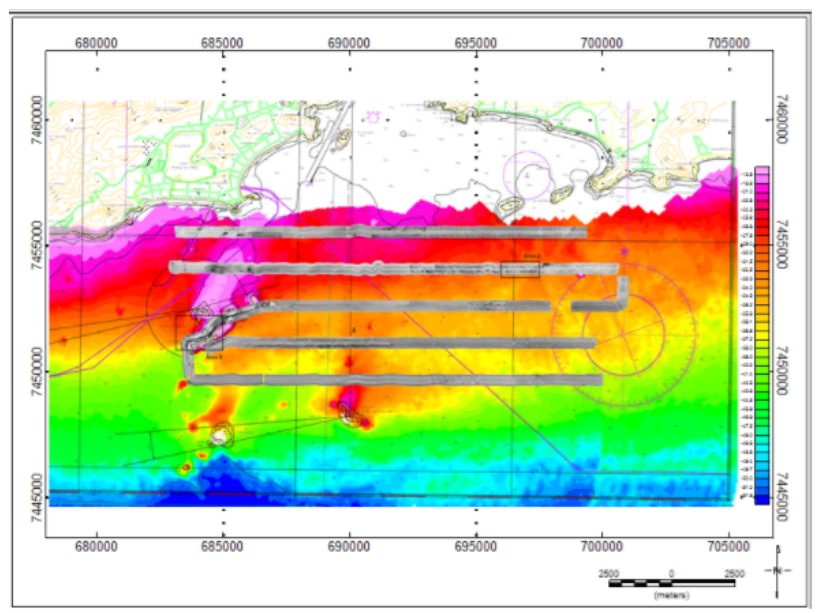

Figura 1 - Mapa de localização da área de estudo.

Ambos os sistemas receberam os dados de posicionamento diretamente do DGPS, já com as devidas correções (offset e lay-back), obtendo coordenadas em tempo real, o que tornou possível georreferenciar cada pixel das imagens sonográficas e sísmicas realizadas. Além disso, ambos os equipamentos foram utilizados concomitantemente e paralelamente, rebocados na embarcação.

\section{Resultados}

Após a aquisição e processamento dos dados tanto da sísmica quanto do sonar de varredura lateral, foi possível observar uma boa correlação entre os sinais dos dois diferentes métodos utilizados. Com as linhas prontas para interpretação, a sonografia foi o primeiro método a ser observado, por ser uma área extensa, com o diagnóstico de mudanças no fundo marinho, poderia ser feito um estudo mais específico usando os dados da sísmica de alta resolução. Com uma observação mais regional, foi mapeado três tipos diferentes de padrões sonográficos, apresentados na figura $2(\mathrm{~A}, \mathrm{~B}, \mathrm{C})$. A partir dessas áreas de interesse foram feitos recortes nas linhas sísmicas para um estudo mais detalhado, como visto, na figura 2 (D, E, F). Com essa visualização, ficou nítido poder classificar, agora de forma regional, todas as anomalias presentes neste estudo. As figuras $D, E$ e $F$ foram plotadas em um mosaico juntamente com a imagem do sidescan sonar, para facilitar a visualização e localização das feições.

$\mathrm{Na}$ figura 2 (A, D), o sonograma apresenta sinal homogêneo, com padrão de cinza claro e na sísmica um refletor forte sem penetração. Este fundo foi classificado como arenoso.

A figura $2(B, E)$, apresenta uma anomalia com alta refletividade e na sísmica é possível se observar um mergulho em um dos refletores, tendo sido classificado como fundo rochoso adjacente a ilha de Cagarras.

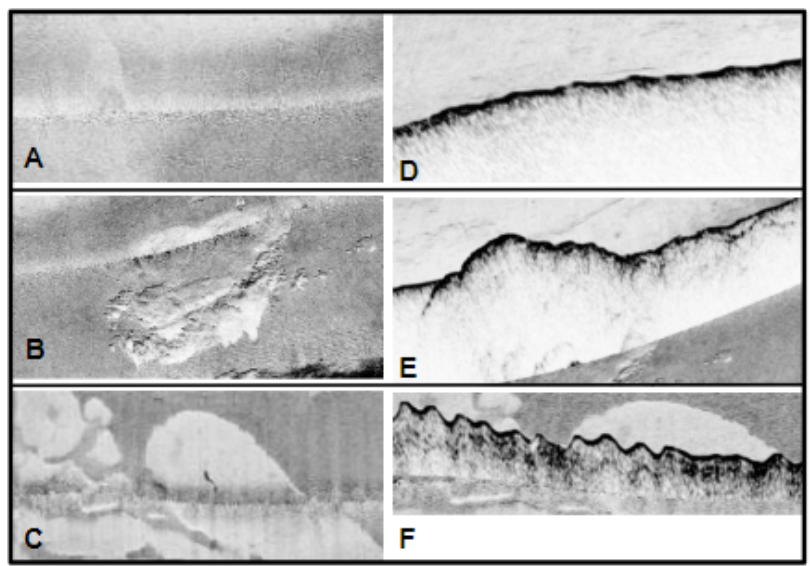

Figura 2 - Imagens do sonar de varredura lateral, a esquerda e de seus respectivos ecofácies sísmicos de três regiões da Baía de Guanabara.

Na figura 2 (C, F), na imagem de sonar foi observado um padrão de "manchas" brancas com extensões de até 80 metros de largura. Essas manchas são intercaladas com o mesmo padrão obtido na figura $2 \mathrm{~A}$, ou seja, fundo arenoso. Dessa forma, intui-se que as manchas correspondem ao depósito de material dragado. A sísmica apresentou um padrão similar ao fundo arenoso, mas com uma resposta mais caótica devido à maior penetração. Estas áreas foram classificadas como as áreas de "despejo" e de dispersão dos sedimentos contaminados.

$\mathrm{Na}$ figura $\mathrm{F}$, é possível observar uma aparente dispersão do sinal abaixo dos refletores. Tal comportamento foi associado principalmente à algum ruído eletrônico, que esteve presente em boa parte do levantamento.

Com essas diferentes respostas observadas no mapeamento realizado na plataforma continental foi possível caracterizar as áreas mais impactadas da região (Figura 3). Estas imagens confirmaram as áreas indicadas pelas agências ambientais do Estado do Rio de Janeiro, como sendo áreas de despejos para estes sedimentos.

Foram feitas algumas análises usando as linhas sísmicas de forma mais regional, como feito com sidescan sonar. Como observado na figura 4, onde foi utilizado um exagero vertical para se ressaltar as anomalias, foi possível correlacionar as respostas dos dois métodos para as mesmas regiões da plataforma continental rasa do Rio de Janeiro. 


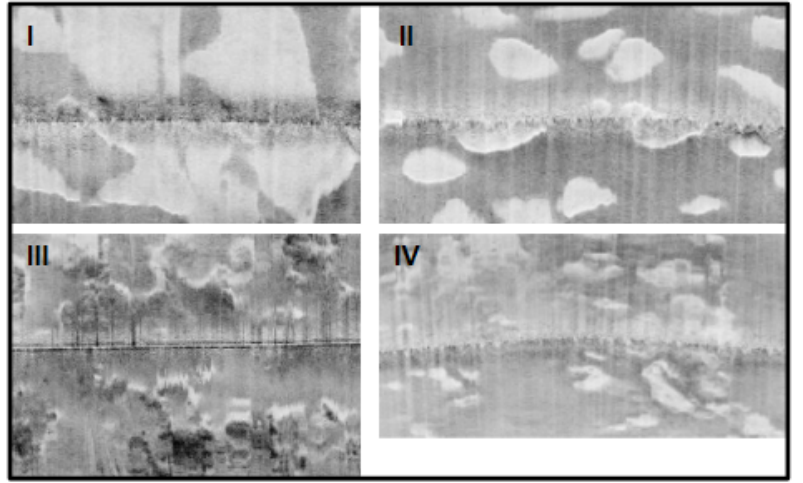

Figura 3 - Mosaico com as imagens de sidescan das áreas com resposta análoga.

A geofísica rasa se apresenta como uma importante ferramenta, não só para a localização das áreas de despejos, associada com o método direto (amostras de fundo - granulometria e geoquímica), mas também para o monitoramento da evolução do comportamento destes sedimentos na área da plataforma continental.

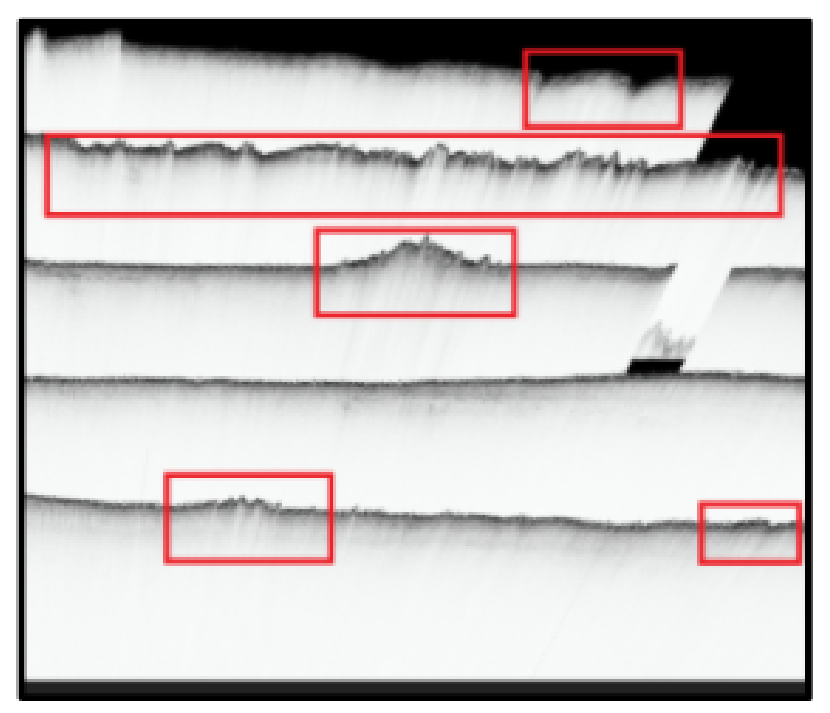

Figura 4 - Linhas sísmicas, com exagero vertical, do levantamento regional.

\section{Conclusão}

A utilização de dois diferentes métodos geofísico permitiram mapear as alterações morfológicas provocadas pelos despejos dos sedimentos dragados no Porto do Rio de Janeiro. Os dados coletados confirmaram os locais de despejo estabelecidos pelo Instituto Estadual do Ambiente - INEA. No entanto, como se observa nos perfis geofísicos, a área da segunda linha de aquisição, a região impactada é bem maior do que a área delimitada para o despejo, o que pode ter sido provocado pela dispersão dos sedimentos ou o despejo ter sido realizado em área maior.

As assinaturas acústicas da área de despejo apresentaram melhor penetração do que nas áreas típicas de plataforma continental rasa, com um fundo arenoso. A região de despejo se comportou, em geral, como um refletor razoavelmente definido. Suas variações são atribuídas à sua composição predominantemente formadas por sedimentos lamosos, distintos dos sedimentos arenosos típicos da plataforma rasa.

$\mathrm{O}$ arenito de praia, marcado na sísmica, apresentou um bom marcador das regiões de despejo. Entretanto, é necessário um estudo direto para averiguar o dano local do despejo, via coleta de sedimentos.

Os métodos geofísicos se mostraram eficientes não só para classificar as áreas afetadas pelos despejos de sedimentos dragados do porto do Rio de Janeiro, mas também, para o futuro monitoramento da evolução deste material na plataforma, assim como melhorar o entendimento a dinâmica sedimentar na área.

\section{Referências}

Baptista Neto, J.A., Brehme, I., Gingele, F.X. \& Leipe, T. (2006). "Spatial distribution of heavy metals in surficial sediments from Guanabara Bay: Rio de Janeiro, Brazil". Environmental Geology. 49: 1051-1063.

Frenzel, P., Borrmann, C., Lauenburg, B., Bohling, B., Bartholdy, J., 2009. Environmental impact assessment of sediment dumping in the southern Baltic Sea using meiofaunal indicators. Journal of Marine Systems 75, 430-440

Kjerfve, B; Lacerda, L.D.; Dias, G.T.M. (2001). Baía de Guanabara, Rio de Janeiro, Brazil. In: Coastal Marine Ecosystems of Latin America. Org. Kjerfve, B.; Seeliger, U. Springer. Volume 144 of the series Ecological Studies . p.107-117.

Harvey, M., Gauthier, D., Munro, J., 1998. Temporal changes in the composition and abundance of macro-benthic invertebrate communities at dredged material disposal sites in the Anse a' Beaufils, Baie de Chaleurs, Eastern Canada. Marine Pollution Bulletin 36 (1), 41-55.

Pereira, T.G. (2013). Abordagem multimetodológica sobre o despejo de sedimentos de dragagem em área de descarte oceânico - plataforma adjacente à Baia de Guanabara. Niterói: Universidade Federal Fluminense. Tese (Doutorado em Dinâmica dos Oceanos e da Terra). $282 \mathrm{p}$.

Regoli, F., Pellegrini, D., Winston, G.W., Gorbi, S., Giuliani, S., Virno-Lamberti, C., Bompadre, S., 2002. Application of biomarkers for assessing the biological impact of dredged materials in the Mediterranean: the 
MAPEAMENTO DOS IMPACTOS AMBIENTAIS DOS REJEITOS DA DRAGAGEM DO PORTO DO RIO DE JANEIRO

relationship between antioxidant responses and susceptibility to oxidative stress in the red mullet (Mullus barbatus). Marine Pollution Bulletin 44, 912-922. 